\title{
Subjective Well-Being of Young People in Therapeutic Residential Care from a Gender Perspective
}

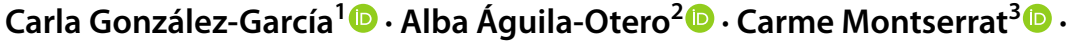

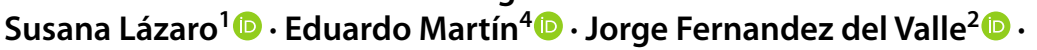 \\ Amaia Bravo ${ }^{2}$
}

Accepted: 9 October 2021 / Published online: 28 October 2021

(C) The Author(s) 2021, corrected publication 2022

\begin{abstract}
A growing body of research focus on subjective well-being (SWB) in adolescence; however there are few studies focus specifically on the residential care population and even fewer on differences by type of residential facility separately for males and females. This study aims to analyze SWB in therapeutic residential care (a residential program created to address youths with severe emotional and behavioral problems) in relation to young people in other kinds of residential child care (RCC). 567 adolescents aged 14-18 from Therapeutic Residential Care (TRC) $(n=256)$ and RCC $(n=311)$ participated in the study. Results showed few significant differences concerning the residential program factor. Satisfaction with their own family was greater for young people in TRC and satisfaction, both with the groups they belong to and with their own residential facility, rated higher among the RCC group. Regarding differences by sex, females reported less SWB in all the domains including overall life satisfaction. The effect of the interaction between sex and type of residential program showed that females in TRC reported SWB, particularly low. The main implications for research and intervention will be discussed.
\end{abstract}

Keywords Subjective well-being $\cdot$ Residential child care $\cdot$ Adolescents $\cdot$ Gender differences

\section{Introduction}

\subsection{Subjective Well-Being in Adolescence}

Since the beginning of the 21st century, an ever-growing number of publications have reported on studies of children's satisfaction with life. As Casas

Amaia Bravo

amaiabravo@uniovi.es

Extended author information available on the last page of the article 
(2017) has noted, these data have also been included as indicators of wellbeing in international reports, such as HBSC 2009/10 (Currie et al., 2012) or UNICEF (for instance, Report Card 13, 2016). The latter report includes data from EU and OECD countries concludes that in recent years of economic crisis children's life satisfaction has deteriorated, thereby increasing the distance between those in the highest and lowest ranges, a trend similarly observed in terms of economics (UNICEF, 2016).

There is a fair degree of agreement regarding how subjective well-being (SWB) evolves with age, since recent studies indicate that satisfaction with life and most of its domains decreases steadily during adolescence (Casas \& González-Carrasco, 2019). Likewise, consensus is emerging about which subgroups of the child population on average display less SWB than their peers. In this respect, the study by Casas, Bello, et al. (2013) identified some such subgroups, like children whose parents are unemployed, who suffer economic and material deprivation, family instability, are migrating, feel unsafe at home or at school, and who exhibit low social participation. Especially relevant to SWB is the perception of feeling poorer than other children at school (Montserrat, Casas \& Moura, 2015). The relationship between low levels of SWB and difficulties in accessing material resources has also been highlighted in an international comparison by Main et al. (2019).

\subsection{Subjective Well-Being and Residential Care}

Residential child care (RCC) involves a large network of residential resources for out-of-home care, usually for the most damaged children and adolescents requiring attention that cannot be provided in a family context, such as kinship care or family foster care. Spanish national statistics indicate that 49,985 children and adolescents were in out-of-home care in 2018; just over a half (52\%) were in residential child care (Observatorio de la Infancia [Childhood Observatory], 2019). The Spanish residential care network consists of different types of facilities; excluding homes for unaccompanied asylum-seeking children, the most important given the proportion of children and young people are children's homes, autonomy programs for adolescents in transition to adulthood, and Therapeutic Residential Care (TRC). TRC is defined as those specialized resources that address cases with severe emotional and behavioral problems as described by Whittaker et al. (2015):

Therapeutic Residential Care involves the planful use of a purposefully constructed, multi-dimensional living environment designed to enhance or provide treatment, education, socialization, support, and protection to children and youth with identified mental health or behavioural needs in partnership with their families and in collaboration with a full spectrum of community based formal and informal helping resources (p. 24). 
International research has shown that adolescents in RCC represent a vulnerable population, evincing high rates of victimization and mental health problems (Fernandez-Artamendi et al., 2020; González-García et al., 2017), as well as high percentages of delinquent behavior, running away, substance abuse, and suicidality, among other problematic behaviors (Attar-Schartz, 2013; Bonet et al., 2020; Katz et al., 2020; Traube et al., 2016). These figures are particularly high in adolescents placed in TRC, describing a more complex social, educational, and behavioral profile. According to recent studies in Spain, this profile is more complex in females, revealing significantly more experiences of victimization (Fernandez-Artamendi et al., 2020) and more risk factors (Águila-Otero et al., 2020).

Little is known about the SWB of adolescence in out-of-home care. Previous studies indicate that they report significantly inferior well-being than their peers in kinship and non-kinship foster care in Spain (Llosada-Gistau et al., 2017), young people leaving care in Israel (Dinisman et al., 2013), or than those in family foster care in England (Selwyn et al., 2016; Wood \& Selwyn, 2017). Wood \& Selwyn explain how the paths of abuse, care placements, having to be continuously in contact with professionals, along with the uncertainty surrounding leaving care, are all factors that impact the well-being of children in care (Wood \& Selwyn, 2017). Similarly, some studies that highlight how important interpersonal relationships are for life satisfaction, as well as feeling listened to by the adult decision-makers (Tonon et al., 2016). Moreover, the relevance of the social support from key persons should be highlighted as one of the single most relevant external factors in maintaining homeostasis in the face of adversity (Cummins \& Wooden, 2014).

In a study by Llosada-Gistau et al. (2019) comparing SWB among adolescents in RCC, kinship care, and their peers in the general population, those in residential care revealed significantly lower SWB than the other two groups. The aspects that contributed the most to SWB for all three groups were feeling safe, their use of time, and the opportunities they have in life, although the weight of these three variables together accounted for a greater percentage of the subjective well-being of children in RCC. Most notably for the purposes of this article, females scored lower than males in RCC on the overall life satisfaction scale; albeit the same was not observed in the other two groups. Nevertheless, there is no further evidence of this finding, except Martín (2015), who observed how young women in residential care present greater difficulties in the processes of social and labor inclusion, with much higher unemployment rates compared to their males' counterparts. This points to the possible influence of the traditional gender roles that persist in our society, according to which women perform care roles towards others more often than males, quitting the studies and jobs that could promote their autonomy. 


\subsection{The Current Study}

Despite the fact that there is a growing body of literature on SWB in the child population, few studies focus specifically on the RCC population and even fewer, on therapeutic residential care samples. One significant gap in particular is the analysis of differences by type of residential program (RCC or TRC) by sex.

Consequently, the general aim of this research is to examine SWB among adolescents in residential child care. This aim is divided in two more specific objectives: first, to carry out a comparative analysis of SWB among adolescents in TRC in relation to young people in other kinds of RCC. Second, to probe the differences in SWB separately for males and females paying special attention to females in TRC in light of the results of earlier studies.

\section{Method}

\subsection{Participants}

The sample consisted of 567 adolescents (53.8\% male; $46.2 \%$ female), aged $14-18$ years $(M=15.65 ; S D=1.03)$. We divided the sample in two types of residential child care programs: therapeutic residential care (TRC), defined as specific services for young people with severe emotional and behavioral problems $(n=256)$, and other types of residential child care (RCC) including regular children's homes without a specific purpose, that generally place children and adolescents of different ages, sibling groups, etc., and some residential care programs for older adolescents in preparation for their transition to independent adulthood $(n=311)$.

There were no significant age differences between both groups (TRC: $\mathrm{M}=$ 15.59 , SD $=1.03$; RCC: $\mathrm{M}=15.72, \mathrm{SD}=1.04$ ), although significant differences did exist with respect to sex (TRC $=65.2 \%$ males and $34 \%$ females; $\mathrm{RCC}$ $=44.4 \%$ males and $55.6 \%$ females $)\left[\chi^{2}(1.567)=24.59 ; p<.001\right]$. As shown by previous research, TRC programs in Spain include more males than females (Águila-Otero et al., 2020).

Participants were adolescents from several regions of Spain in order for it to be more representative of different regional authorities and cultural contexts: Asturias, Basque Country, Cantabria, Galicia, Madrid, Extremadura, Murcia, Catalonia, Tenerife, and seven SOS Children's Villages. Adolescents with serious comprehension and reading difficulties were previously identified by their social educators and were not included in the study. 


\subsection{Instrument}

We used the Spanish adaptation of the Personal Wellbeing Index (PWI; Cummins \& Lau, 2005), designed as part of the Australian Unit Wellbeing Index, a multi-item tool that originally included seven items of satisfaction with different life domains. The PWI scored from 0 (completely dissatisfied) to 10 (completely satisfied) and includes: your health; your standard of living; your life achievements; your safety; groups of people you belong to; your future security, and your interpersonal relationships. The psychometric properties of PWI have been reported in several studies (Lau et al., 2005). The scale was designed to be used with adults; nevertheless, it has also been utilized with adolescents and continued to display good psychometric properties (Casas, Bello et al., 2013). Due to the special situation of the young people in our sample (placed in residential child care), we have added three more items that refer to satisfaction with their own family, how they have fun, and their body (these items were included in the PWI-SC version for children), as well as another item about satisfaction with their residential care facility (in an attempt to probe this special context of their lives).

Similarly, we included the single-item Overall Life Satisfaction Scale (OLS). Authors like Campbell et al. (1976) have spoken to the importance of including this overall satisfaction item. Both scales have been administered to residential care samples and have yielded interesting results as a measure of SWB in young people in RCC (Llosada-Gistau et al., 2015, 2017). Cronbach's alpha was calculated to quantify the scale's internal consistency (0.89).

\subsection{Procedure}

The study obtained the ethical approval from the the Ethics Committee of La Laguna University (Tenerife) and it was also guaranteed the requirements of the Spanish Law regarding Personal Data Protection. Data were collected after obtaining legal permission from tutors and regional authorities of child welfare services in each region. Once the research project received ethical approval and permissions, the researchers contacted all the residential facilities to explain the objectives and procedures. Likewise, they visited each residential home to explain the project to the young people, obtain their informed consent, and supervise the completion of the questionnaires.

\subsection{Data Analysis}

Statistical analysis consisted of a two-way ANOVA with sex (male-female) and program (TRC-RCC) as the main factors; we also examined the interaction factor. Effect size was estimated using partial eta squared $\left(\eta^{2}\right)$ and we performed all analysis with SPSS 24 statistics program. 
Table 1 SWB descriptive data (means and standard deviations) by group

\begin{tabular}{llllll}
\hline & \multicolumn{2}{l}{ NON TRC } & & \multicolumn{2}{l}{ TRC } \\
\cline { 2 - 3 } \cline { 6 - 6 } & $\mathrm{M}$ & $\mathrm{SD}$ & & $\mathrm{M}$ & $\mathrm{SD}$ \\
\hline Family & 6.64 & 3.35 & & 7.93 & 2.851 \\
Health & 7.57 & 2.48 & & 7.76 & 2.46 \\
Standard of living & 6.96 & 2.70 & & 6.76 & 3.05 \\
Life achievements & 6.88 & 2.87 & & 6.96 & 4.61 \\
Your safety & 6.98 & 2.81 & & 6.90 & 2.93 \\
Groups you belong to & 8.11 & 2.23 & & 7.70 & 2.57 \\
Future security & 6.25 & 2.99 & & 6.49 & 3.07 \\
Relationships & 7.90 & 2.14 & & 7.74 & 2.54 \\
The way you have fun & 8.37 & 2.25 & & 8.11 & 2.46 \\
Your body & 6.92 & 3.08 & & 7.34 & 3.19 \\
Residential facility & 6.75 & 3.19 & & 5.28 & 3.67 \\
Life as a whole (OLS) & 6.91 & 2.71 & 6.76 & 3.00 \\
\hline
\end{tabular}

\section{Results}

Descriptive data (means and standard deviations) of each group can be found in Table 1. The ANOVA results (Table 2) revealed few significant differences with respect to the program factor. Satisfaction with their own family was greater for young people in TRC and satisfaction, both with the groups they belong to and with their own residential facility, rated higher among the RCC group.

However, the sex factor exhibited significant differences on all items except family and residential facility; females revealed lower satisfaction in all cases. These differences were particularly high with respect to their feeling of safety and satisfaction with their body, generating moderate effect sizes $\left(\mathrm{h}^{2}=\right.$ .07-.09).

Interaction effects demonstrated significant differences only on the items having to do with satisfaction with their standard of living, safety, and on the OLS that also presented significant effects for sex. As Figs 1, 2, and 3 illustrate, the pattern of interaction between program and sex is quite similar: females in TRC have a clearly different and worse perception of their satisfaction on those three domains, with their low satisfaction with their lives as a whole particularly relevant. Consequently, adding the two significant effects (sex and interaction) results reveal that females are less satisfied with those three domains than males, but females in TRC have a particularly poor senses of wellbeing. 
Table 2 Means, Standard Deviations, and Two-Way ANOVA Statistics for Study Variables

\begin{tabular}{|c|c|c|c|c|c|c|c|}
\hline & \multicolumn{2}{|c|}{ NON-TRC } & \multicolumn{2}{|l|}{ TRC } & \multicolumn{3}{|c|}{ ANOVA } \\
\hline & M & SD & M & SD & Effect & $F$ Ratio & $h^{2}$ \\
\hline Family & & & & & $\mathrm{P}$ & $19.05^{* *}$ & .03 \\
\hline Boys & 6.87 & 3.23 & 8.10 & 2.88 & G & 2.72 & .01 \\
\hline Girls & 6.46 & 3.45 & 7.93 & 3.28 & $\mathrm{P} * \mathrm{G}$ & 0.02 & .00 \\
\hline Health & & & & & $\mathrm{P}$ & 0.21 & .00 \\
\hline Boys & 7.87 & 2.40 & 7.89 & 2.42 & G & $4.50^{*}$ & .01 \\
\hline Girls & 7.33 & 2.53 & 7.51 & 2.54 & $\mathrm{P}^{*} \mathrm{G}$ & 0.15 & .00 \\
\hline Standard of living & & & & & $\mathrm{P}$ & 3.34 & .00 \\
\hline Boys & 7.13 & 2.79 & 7.28 & 2.88 & G & $13.47^{* *}$ & .02 \\
\hline Girls & 6.82 & 2.63 & 6.76 & 3.05 & $P^{*} \mathrm{G}$ & $6.04^{*}$ & .01 \\
\hline Life achievements & & & & & $\mathrm{P}$ & 0.15 & .00 \\
\hline Boys & 6.99 & 2.73 & 7.42 & 5.25 & G & $5.31^{*}$ & .01 \\
\hline Girls & 6.79 & 2.99 & 6.96 & 4.61 & $\mathrm{P} * \mathrm{G}$ & 2.84 & .00 \\
\hline Your Safety & & & & & $\mathrm{P}$ & 3.63 & .01 \\
\hline Boys & 7.37 & 2.61 & 7.70 & 2.40 & G & $38.42^{* *}$ & .07 \\
\hline Girls & 6.66 & 2.94 & 5.40 & 3.25 & $\mathrm{P}^{*} \mathrm{G}$ & $10.75^{* *}$ & .02 \\
\hline Groups you belong to & & & & & $\mathrm{P}$ & $6.68^{*}$ & .01 \\
\hline Boys & 8.31 & 2.22 & 7.95 & 2.44 & G & $6.81^{* *}$ & .01 \\
\hline Girls & 7.95 & 2.23 & 7.24 & 2.75 & $\mathrm{P} * \mathrm{G}$ & 0.71 & .00 \\
\hline Future security & & & & & $\mathrm{P}$ & 0.07 & .00 \\
\hline Boys & 6.33 & 2.92 & 6.86 & 2.84 & G & $5.17^{*}$ & .01 \\
\hline Girls & 6.20 & 3.05 & 5.80 & 3.39 & $\mathrm{P} * \mathrm{G}$ & 3.17 & .01 \\
\hline Relationships & & & & & $\mathrm{P}$ & 1.76 & .00 \\
\hline Boys & 8.07 & 2.02 & 7.96 & 2.43 & G & $5.30^{*}$ & .01 \\
\hline Girls & 7.76 & 2.24 & 7.33 & 2.71 & $\mathrm{P}^{*} \mathrm{G}$ & 0.58 & .00 \\
\hline The way you have fun & & & & & $\mathrm{P}$ & 3.22 & .01 \\
\hline Boys & 8.76 & 1.96 & 8.26 & 2.32 & G & $7.89^{* *}$ & .01 \\
\hline Girls & 8.05 & 2.43 & 7.82 & 2.72 & $\mathrm{P} * \mathrm{G}$ & 0.43 & .00 \\
\hline Your body & & & & & $\mathrm{P}$ & 0.01 & .00 \\
\hline Boys & 7.71 & 2.67 & 8.18 & 2.53 & G & $53.84^{* *}$ & .09 \\
\hline Girls & 6.29 & 3.24 & 6.12 & 3.37 & $\mathrm{P}^{*} \mathrm{G}$ & 3.58 & .01 \\
\hline Residential facility & & & & & $\mathrm{P}$ & $25.65^{* *}$ & .04 \\
\hline Boys & 6.57 & 3.40 & 5.42 & 3.74 & G & 0.03 & .00 \\
\hline Girls & 6.89 & 3.03 & 4.99 & 3.54 & $\mathrm{P} * \mathrm{G}$ & 1.60 & .00 \\
\hline Life as a whole (OLS) & & & & & $\mathrm{P}$ & 2.89 & .00 \\
\hline Boys & 7.02 & 2.75 & 7.34 & 2.76 & G & $14.93^{* *}$ & .03 \\
\hline Girls & 6.82 & 2.69 & 5.66 & 3.16 & $\mathrm{P} * \mathrm{G}$ & $9.10^{* *}$ & .02 \\
\hline
\end{tabular}

$N=567 . d f=1$. ANOVA=analysis of variance; TRC: therapeutic residential care; NON-TRC: Non therapeutic residential care; P: Program; G: Gender

$* p<0.05 * * p<0.01$ 
256

C. González-García et al.

8

7.5

7

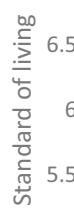

5

4.5

Boys - - Girls

4

IRC

REC

Fig. 1 Interaction effect of Two-Way ANOVA for the item standard of living

8

7.5

7

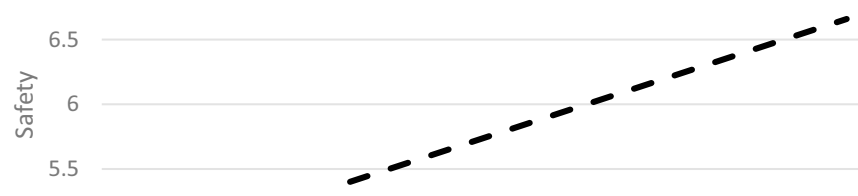

5

4.5

Males - - Females

4

IRC

REC

Fig. 2 Interaction effect of Two-Way ANOVA for the item safety

Springer 


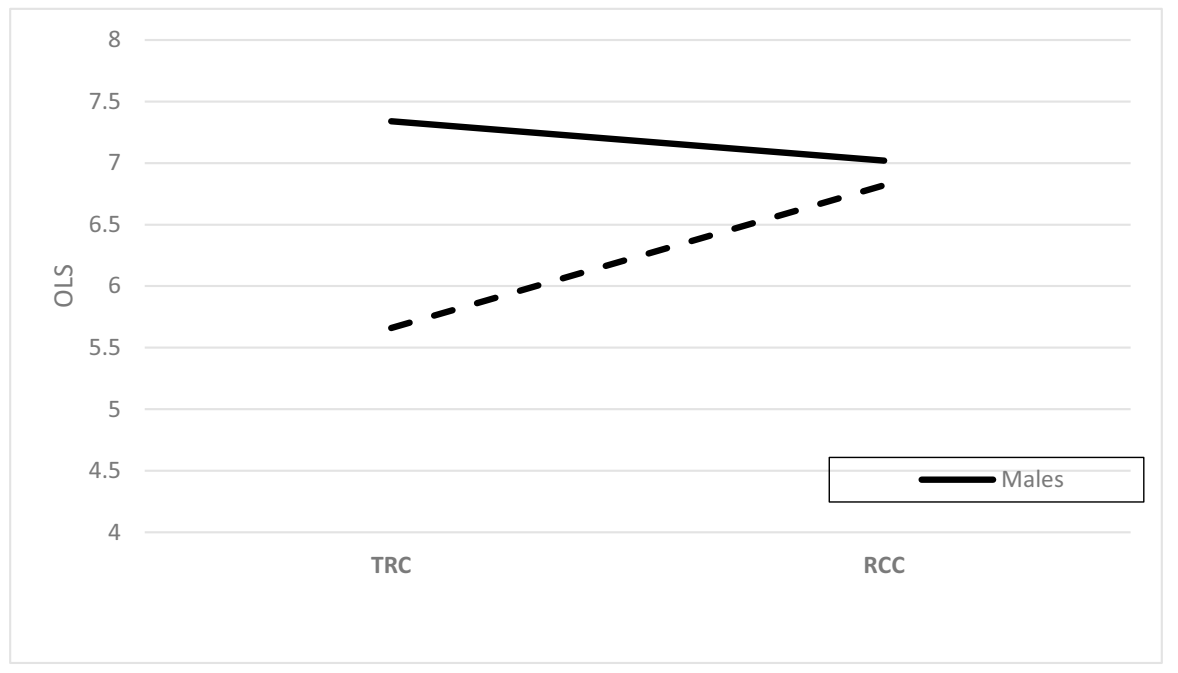

Fig. 3 Interaction effect of Two-Way ANOVA for OLS (Overall life satisfaction)

\section{Discussion}

The main objective of this study was to examine the subjective wellbeing of adolescents in residential care, factoring in the influence of the type of program (TRC and ordinary RCC network) and paying special attention to differences between males and females.

It is important to begin by highlighting the low degree of overall life satisfaction (OLS) in the sample as a whole, consistent with the results of earlier works (Llosada-Gistau et al., 2015, 2017, 2019). In a study of Spanish adolescents from the general population, Casas, Fernández-Artamendi et al. (2013) detected a mean of 8.01 for overall satisfaction versus the mean 6.84 for our entire sample. As Wood and Selwyn (2017) pointed out, the consequences of the situations experienced in their families, together with the uncertainty surrounding the end of the protection measure or dependence on professional help in their daily lives are all factors that negatively impact the wellbeing of children and young people in care.

Inasmuch as the results of our comparative analyses are concerned, very few differences have been found in the wellbeing of adolescents when both types of programs are compared, since significant differences were only observed with respect to their satisfaction with their residential home and with their family. On the one hand, the TRC group displayed less satisfaction with their residential facility. In line with this, other research revealed adolescents in these types of programs tend to be highly critical of certain aspects of these specialized programs, such as control and very intense security measures (in fact, many of them are locked spaces), with security personnel and a very controlled atmosphere (Pérez-García et al., 2019). Similarly, other authors have emphasized serious social, educational, and behavioral issues among adolescents in TRC and greater resistance to the intervention they can be offered, possibly linked to previous 
therapeutic failure (Aventin et al., 2014; Martín et al., 2018). On the other hand, the group in TRC exhibits greater satisfaction with their family, something that is likely accounted for by the profiles of referrals to TRC are severe problems with inability to control their children's behavior (Águila-Otero et al., 2020) and, in these cases, there may not be any serious experiences of mistreatment or abuse that typically characterize the profiles of child care in other instances.

By contrast, the effect of sex was significant for all the domains assessed, with the exception of the previous two (family and residential facility) that have been shown to be determined by the program factor. Overall, females perceived less subjective wellbeing in all the other aspects, including on the OSL. These results are highly relevant, in light of the paucity of research in the field of residential child care that reflect the gender perspective. Although some earlier studies in the general population yield contradictory outcomes, from finding no significant gender-linked differences with respect to life satisfaction (Huebner, 2004; Proctor et al., 2009; Rees et al., 2010) to revealing less satisfaction among females in general (Burke and Minton, 2019) and particularly in adolescence, highlighting the role of gender as an important factor in explaining differences in subjective wellbeing (EstebanGonzalo et al., 2020). The scant, recent research in children and young people in care are consistent with the results found in this work and point to females in residential facilities score lower on overall satisfaction with their life (Llosada-Gistau et al., 2019). Montserrat, Dinisman et al. (2015) points toward female adolescents may feel especially influenced by critical changes in their lives, including the change in where they life or in their caregivers, with a negative impact on their wellbeing. To strengthen the gender analysis and discuss the results with a more thorough understanding of the mechanisms creating gender inequalities is SWB, two domains are especially salient in which the difference reach moderate effect sizes: feeling of safety and satisfaction with their own body. With respect to the latter, this result is in line with that of the general adolescent population, attributed to the pressure of the body esthetic model found on social media (Maganto et al., 2016). Goldbeck et al. (2007) allege a more critical self-perception in female adolescents in the face of the physical changes that occur in puberty, in an atmosphere in which the standards of beauty exert great pressure. In contrast, the feeling of being less safe is a particularly relevant domain, given the significance that it has on everyday emotional wellbeing and probably has to do with the climate of vulnerability that women have been condemning in the face of gender violence, sexual relations, or even insecurity on the streets. Our sample comprises young people who do not have the protection normally provided by the family, which can augment this feeling of vulnerability. Another domain on which the females were less satisfied is that of interpersonal relationships, on which females in the general population express less satisfaction (Kaye-Tzadok et al., 2017). The effect of the interaction between males and females and type of residential program clearly reveals that among females in TRC, their subjective wellbeing is especially low in such key areas as overall life satisfaction, feeling of safety, and standard of living. This result must be underscored, as it enables us to conclude that, although adolescents in TRC are referred to this program because of their severe emotional and behavioral problems, this personal situation does not appear to affect males' perception of personal wellbeing compared to the 
males in another kind of residential care. On the other hand, these emotional and behavioral issues do seem to significantly impair females' perception of wellbeing; this is probably due to these problems being much more severe. Indeed, earlier research conducted with samples of young people in TRC has determined that the severity of the problems in females is much greater than in males, and this aspect can contribute also to explain the gender differences as girls are less frequently referred to TRC unless they have highly severe emotional problems. In a large sample of TRC, Águila-Otero et al. (2020) found twice as many cases within the clinical range on the Youth Self-Report (YSR) in the females on the anxious/ depressed and social scales, as well as double the suicide attempts and need for psychiatric hospitalization. Likewise, clear differences were detected with respect to experiences related to sexuality, such as unwanted pregnancy or beginning prostitution. Likewise, and also in a TRC sample, Fernández-Artamendi et al. (2020) conclude that females experienced more victimization and in other areas, specifically, poly-victimization associated with greater alcohol consumption. Perhaps all these aspects are related to the result shown by Esteban-Gonzalo et al. (2020) found out in relation to the existence of significant gender differences with lower scores in purpose in life among girls.

\section{Conclusions}

It can be concluded that, despite the fact that most adolescents referred to TRC are male (two thirds), the profile of female referrals is highly specific, with more severe emotional issues and more negative experiences of victimization than males. This may account for the lower level of subjective wellbeing perceived by the females in TRC, which adds to the overall tendency of females toward a lower perception of subjective wellbeing in residential care in general. All of this points to the need to bear in mind the gender perspective for both the research into and intervention in child care, but very particularly in TRC, where the level of wellbeing is extremely low, even in comparison to the male young people who must also be referred to these specific programs. This gender perspective should be complemented with the intersectionality approach as a theoretical framework (Crenshaw, 1991) that relates differential attributes that enhance inequality such as social class, ethnic group, gender identity, sexual orientation, or disability. From this theory, all these categories are analyzed, not separately, but as combinations or constellations that multiply the risks of inequality and social exclusion. Few social groups reveal this diversity of concurring factors so manifestly as that of young women in residential care.

Funding Open Access funding provided thanks to the CRUE-CSIC agreement with Springer Nature. This research study was supported by the Ministry of Economy and Competitiveness (MINECO) of Spain through the National Plan of I + D + i (PSI2015-65229-R and PSI2012-33185). The author Alba Águila-Otero holds a post-doctoral scholarship from the Severo Ochoa Program for Training in Research and Teaching in the Principality of Asturias (BP16061).

\section{Declaration}

Conflicts of Interest we have no conflict of interest to disclose 
Open Access This article is licensed under a Creative Commons Attribution 4.0 International License, which permits use, sharing, adaptation, distribution and reproduction in any medium or format, as long as you give appropriate credit to the original author(s) and the source, provide a link to the Creative Commons licence, and indicate if changes were made. The images or other third party material in this article are included in the article's Creative Commons licence, unless indicated otherwise in a credit line to the material. If material is not included in the article's Creative Commons licence and your intended use is not permitted by statutory regulation or exceeds the permitted use, you will need to obtain permission directly from the copyright holder. To view a copy of this licence, visit http://creativecommons.org/licen ses/by/4.0/.

\section{References}

Attar-Schartz, S. (2013). Runaway behavior among adolescents in residential care. The role of personal characteristics, victimization experiences while in care, social climate and institutional factors. Children and Youth Services Review, 35, 258-263. https://doi.org/10.1016/j.childyouth.20132.11.005

Aventin, A., Houston, S., \& Macdonald, G. (2014). Utilising a computer game as a therapeutic intervention for youth in residential care: Some preliminary findings on use and acceptability. Children and Youth Services Review, 47, 362-369. https://doi.org/10.1016/j.childyouth.2014.10.012

Águila-Otero, A., Santos, I., Bravo, A., \& Del Valle, J. F. (2020). Addressing the most damaged adolescents in the child protection system: An analysis of the profiles of young people in therapeutic residential care. Children and Youth Services Review, 112, 104923. https://doi.org/10.1016/j.child youth.2020.104923

Bonet, C., Palma, C., \& Gimeno-Santos, M. (2020). Riesgo de suicidio, inteligencia emocional y necesidades psicológicas básicas en adolescentes tutelados en centros residenciales [Suicide risk, emotional intelligence and basic psychological needs in adolescents in residential care]. Revista de Psicología Clínica con Niños y Adolescentes, 7(2), 30-37. https://doi.org/10.21134/rpcna.2020.07.1.4

Burke, J., \& Minton, S. J. (2019). Well-being in post-primary schools in Ireland: the assessment and contribution of character strengths. Irish Educational Studies, 38(2), 177-192. https://doi.org/10.1080/ 03323315.2018.1512887

Campbell, A., Converse, P. E., \& Rodgers, W. L. (1976). The quality of American life: Perceptions, evaluations, and satisfactions. Russell Sage Foundation.

Casas, F. (2017). Children's subjective wellbeing and children's rights: new research giving relevance to children's perspectives. Developing Practice Issue, 47, 95-110.

Casas, F., Fernández-Artamendi, S., Bertrán, I., Montserrat, C., Bravo, A., \& Del Valle, J. F. (2013). Adolescents' subjective well-being: A comparative study between two Autonomous Communities in Spain. Anales De Psicología, 29(1), 148-158. https://doi.org/10.6018/analesps.29.1.145471

Casas, F., \& González-Carrasco, M. (2019). Subjective well-being decreasing with age: New research on children over 8. Child Development, 90(2), 375-394. https://doi.org/10.1111/cdev.13133

Casas, F., Bello, A., González, M., \& Aligué, M. (2013). Children's subjective well-being measured using a composite index: what impacts Spanish first-year secondary education students' subjective well-being? Child Indicators Research, 6(3), 433-460. https://doi.org/10.1007/s12187-013-9182-X

Tonon, G., Mikkelsen, C., Rodriguez de la Vega, L., \& Toscano, W. (2016). Children's views on their lives and well-being in 17 countries: Key messages from each country. Children's Worlds, 8

Crenshaw, K. (1991). Mapping the Margins: Intersectionality, Identity Politics, and Violence against Women of Color. Stanford Law Review, 43(6), 1241-1299. https://doi.org/10.2307/1229039

Cummins, R. A., \& Lau, A. L. (2005). Personal wellbeing index - School children, Manual (3rd ed., pp. 74-93). Deakin University.

Cummins, R. A., \& Wooden, M. (2014). Personal resilience in times of crisis: The implications of SWB homeostasis and set-points. Journal of Happiness Studies, 15(1), 223-235. https://doi.org/10.1007/ s10902-013-9481-4

Currie, C., Zanotti, C., Morgan, A., Currie, D., de Looze, M., Roberts, C., \& Rasmussen, V. B. (2012). Social determinants of health and well-being among young people. Health Behaviour in Schoolaged Children (HBSC) study: international report from the 2009/2010 survey. WHO Regional Office for Europe. 
Dinisman, T., Zeira, T., Sulimani-Aidan,Y., \& Benbenishty, R. (2013). The subjective well-being of young people aging out of care. Children and Youth Services Review, 35(10), 1705-1711. https://doi. org/10.1016/j.childyouth.2013.07.011

Esteban-Gonzalo, S., Esteban-Gonzalo, L., Cabanas-Sánchez, V., Miret, M., \& Veiga, O. L. (2020). The Investigation of Gender Differences in Subjective Wellbeing in Children and Adolescents: The UP\&DOWN Study. International journal of environmental research and public health, 17(8), 2732.

Fernández-Artamendi, S., Águila-Otero, A., Del Valle, J. F., \& Bravo, A. (2020). Victimization and substance use among adolescents in residential child care. Child Abuse and Neglect, 104, 104484. https://doi.org/10.1016/j.chiabu.2020.104484

Goldbeck, L., Schmitz, T. G., Besier, T., Herschbach, P., \& Henrich, G. (2007). Life satisfaction decreases during adolescence. Quality of Life Research, 16(6), 969-979. https://doi.org/10.1007/ s11136-007-9205-5

González-García, C., Bravo, A., Arruabarrena, M. I., Martín, E., Santos, I., \& Del Valle, J. F. (2017). Emotional and behavioral problems of children in residential care: Screening detection and referrals to mental health services. Children and Youth Services Review, 73, 100-106. https://doi.org/10. 1016/j.childyouth.2016.12.011

Huebner, E. S. (2004). Research on assessment of life satisfaction of children and adolescents. Social Indicators Research, 66(1/2), 3-33. https://doi.org/10.1023/B:SOCI.0000007497.57754.e3

Katz, C. C., Busby, D., \& McCabe, C. (2020). Suicidal behaviour in transition-aged youth with out-ofhome care experience: Reviewing risk, assessment and intervention. Child and Family Social Work, 25(3), 611-618. https://doi.org/10.1111/cfs.12733

Kaye-Tzadok, A., Sun Suk, K., \& Main, G. (2017). Children's subjective well-being in relation to gender. What can we learn from dissatisfied children? Children and Youth Services Review, 80, 96-104. https://doi.org/10.1016/j.childyouth.2017.06.058

Lau, A. L. D., Cummins, R. A., \& McPherson, W. (2005). An investigation into the cross-cultural equivalence of the Personal Well-Being Index. Social Indicators Research, 72, 403-430. https://doi.org/10. 1007/s11205-004-0561-z

Llosada-Gistau, J., Casas, F., \& Montserrat, C. (2017). What Matters in for the Subjective WellBeing of Children in Care? Child Indicators Research, 10(3), 735-760. https://doi.org/10.1007/ s12187-016-9405-Z

Llosada-Gistau, J., Casas, F., \& Montserrat, C. (2019). The subjective well-being of children in kinship care. Psicothema, 31(2), 149-155. https://doi.org/10.7334/psicothema2018.302

Llosada-Gistau, J., Montserrat, C., \& Casas, F. (2015). The subjective well-being of adolescents in residential care compared to that of the general population. Children and Youth Services Review, 52, 150-157. https://doi.org/10.1016/j.childyouth.2014.11.007

Maganto, C., Garaigordobil, M., \& Kortabarria, L. (2016). Variables antropométricas, hábitos y dietas alimentarias en adolescentes y jóvenes: Diferencias en función del sexo [Anthropometric variables, eating habits and diets in adolescents and youth: Sex differences]. Acción Psicológica, 13(2), 89-100. https://doi.org/10.5944/ap.13.2.17817

Main, G., Montserrat, C., Andresen, S., Bradshawd, J., \& Lee, B. J. (2019). Inequality, material wellbeing, and subjective well-being: Exploring associations for children across 15 diverse countries. Children and Youth Services Review, 97, 3-13. https://doi.org/10.1016/j.childyouth.2017.06.033

Martín, E. (2015). Niños, niñas y adolescentes en acogimiento residencial. Un análisis en función del género [Children and adolescents in residential care. A gender analysis]. Qurriculum, 28, 91-105.

Martín, E., González-García, C., Del Valle, J. F., \& Bravo, A. (2018). Therapeutic residential care in Spain. Population treated and therapeutic coverage. Child and Family Social Work, 23(1), 1-7. https://doi.org/10.1111/cfs.12374

Montserrat, C., Casas, F., \& Moura, J. F. (2015). Children's subjective well-being in disadvantaged situations. In E. Fernandez, A. Zeira, T. Vecchiato, \& C. Canali (Eds.), Theoretical and Empirical Insights into Child and Family Poverty (pp. 111-126). Springer.

Montserrat, C., Dinisman, T., Baltatescu, S., Grigoras, B. A., \& Casas, F. (2015). The Effect of Critical Changes and Gender on Adolescents' Subjective Well-Being: Comparisons Across 8 Countries. Child Indicators Research, 8(1), 111-131. https://doi.org/10.1007/s12187-014-9288-9

Observatorio de la Infancia (2019). Boletín de datos estadísticos de medidas de protección a la infancia. Boletín 21 [Spanish Child Protection Figures. Bulletin 21]. Ministerio de Sanidad, Consumo y Bienestar Social. 
Pérez-García, S., Águila-Otero, A., Santos, I., \& Del Valle, J. F. (2019). No one ever asked us. Young people's evaluation of their residential child care facilities in three different programs. Psicothema, 31(3), 319-326. 10.7334/psicothema2019.129

Proctor, C. L., Linley, P. A., \& Maltby, J. (2009). Youth Life Satisfaction: a review of the literature. Journal of Happiness Studies, 10, 583-630. https://doi.org/10.1007/s10902-008-9110-9

Rees, G., Bradshaw, J., Goswami, H., \& Keung, A. (2010). Understanding children's well-being. A national survey of young people's well-being. The Children's Society.

Selwyn, J., Wood, M. J. E., \& Newman, T. J. (2016). Looked after children and young people in England: Developing measures of subjective well-being. Child Indicators Research, 10(2), 363-380. https:// doi.org/10.1007/s12187-016-9375-1

Traube, D. E., Yarnell, L. M., \& Schrager, S. M. (2016). Differences in polysubstance use among youth in the child welfare system: Toward a better understanding of the highest-risk teens. Child Abuse and Neglect, 52, 146-157. https://doi.org/10.1016/j.chiabu.2015.11.020

UNICEF. (2016). Fairness for Children: A league table of inequality in child well-being in rich countries, Innocenti Report Card 13. UNICEF.

Whittaker, J. K., Holmes, L., \& Del Valle, J. F. (2015). Therapeutic residential care for children and youth. Developing evidence-based international practice. Jessica Kingsley.

Wood, M., \& Selwyn, J. (2017). Looked after children and young people's views on what matters to their subjective well-being. Adoption \& Fostering, 41, 20-34.

Publisher's Note Springer Nature remains neutral with regard to jurisdictional claims in published maps and institutional affiliations.

\section{Authors and Affiliations}

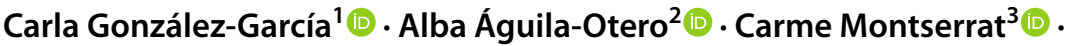 Susana Lázaro ${ }^{1}\left[\right.$. Eduardo Martín ${ }^{4}\left[\right.$. Jorge Fernandez del Valle ${ }^{2}[$. Amaia Bravo²}

Carla González-García

carla.gonzalez.garcia@gmail.com

Alba Águila-Otero

aguilaalba@uniovi.es

Carme Montserrat

carme.montserrat@udg.edu

Susana Lázaro

susana.lazaro@unican.es

Eduardo Martín

edmartin@ull.edu.es

Jorge Fernandez del Valle

jvalle@uniovi.es

1 University of Cantabria, Santander, Spain

2 University of Oviedo, Oviedo, Spain

3 University of Girona, Girona, Spain

4 University of La Laguna, Santa Cruz de Tenerife, Spain 